\title{
Life-Threatening Adverse Reaction after Self-Initiated, Off-Label Use of High Dose Nicotinamide for the Treatment of Friedreich's Ataxia
}

\author{
Nicolas Garin ${ }^{1}$, Pierre Arnold ${ }^{2}$ \\ ${ }^{1}$ Department of Internal Medicine, Regional Hospital Riviera-Chablais, Monthey, Switzerland and \\ Department of Internal Medicine, Geneva University Hospitals, Geneva, Switzerland \\ ${ }^{2}$ Association Suisse de l'Ataxie de Friedreich (aCHaf), Sion, Switzerland
}

Received: 26/05/2015

Accepted: 27/05/2015

Published: $24 / 06 / 2015$

How to cite this article: Garin N, Arnold P. Life-threatening adverse reaction after self-initiated, off-label use of high dose nicotinamide for the treatment of Friedreich's ataxia. EJCRIM 2015;2:doi: 10.12890/2015_000234

Conflicts of Interests: The authors declare that they have no conflicts of interest in this research.

Acknowledgements: N.G. wrote the first and final drafts of the manuscript. P.A. revised the manuscript for critical intellectual content. The patient gave formal informed consent for the publication of her story.

This article is licensed under a Commons Attribution Non-Commercial 4.0 License

\section{ABSTRACT}

A 40-year old woman, previously known for Friedreich's ataxia, presented with shock, profound lactic acidosis and hepatic failure after ingestion of a high dose of nicotinamide, the amide form of vitamin B3. On her own initiative, she was taking up to $4.4 \mathrm{~g}$ per day of nicotinamide, after having learned the results of a phase 2 study suggesting a potential benefit in Friedreich's ataxia. The outcome was good with supportive care and withdrawal of nicotinamide.

\section{LEARNING POINTS}

- High-dose nicotinamide can cause life-threatening shock, lactic acidosis and hepatic failure.

- Extensive use of experimental treatments can lead to unexpected, severe adverse reactions, even with apparently safe over-thecounter products.

- Vulnerable patients with orphan diseases may self-initiate hazardous treatment which is still under investigation.

\section{KEYWORDS}

Niacin, nicotinic acid, nicotinamide, vitamin B3, Friedreich's ataxia, toxicity, intoxication, adverse effect.

\section{INTRODUCTION}

Friedreich's ataxia is a disabling inherited disease characterized by mutations in a gene on chromosome 9 q13 leading to decreased production of frataxin, a mitochondrial protein involved in iron metabolism. The evolution is characterized by progressive ataxia and dysarthria. No causal treatment is yet available. Recently, in an exploratory clinical trial, daily administration of nicotinamide (the amide form of vitamin B3, nicotinic acid being the acidic form) at a dose of 2-8 g increased the concentration of frataxin in patients with Friedreich's ataxia ${ }^{[1]}$. This finding suggested that nicotinamide could favourably affect the course of the disease.

\section{CASE REPORT}

A 40-year-old woman, known for Friedreich's ataxia, was admitted to hospital for shock. She was 18 years old at disease onset, and disease progression was accordingly slow. One month previously, when last seen by her neurologist, she was able to stand up with bilateral support for transfers. Her score on the International Cooperative Ataxia Rating Scale was 67/100. Echocardiography showed no cardiac involvement. She was otherwise in good general health until the day before admission, when she felt nauseous and tired. On the evening, she had vomited and lost consciousness. At first evaluation, she was unconscious. Heart rate was $120 \mathrm{bpm}$, blood pressure 70/43 mmHg, respiratory rate 24 breaths/ min, and oxygen saturation 100\% with supplemental oxygen. Capillary blood glucose was $1.4 \mathrm{mmol} / \mathrm{I}$. Normal saline and $40 \%$ glucose solutions were infused, and she was transferred to hospital. At admission, she was conscious but confused. Heart rate was $101 \mathrm{bpm}$, blood pressure had risen to $102 / 57 \mathrm{mmHg}$ and blood glucose to $5.6 \mathrm{mmol} / \mathrm{l}$. Tympanic temperature was $34.0^{\circ} \mathrm{C}$. Physical examination was unremarkable except for neurological signs of Friedreich's ataxia. ECG showed sinus tachycardia. Chest and plain abdominal x-rays were unremarkable. Blood tests showed profound lactic acidosis, coagulopathy and leukocytosis (Table 1). 


\begin{tabular}{|c|c|c|c|c|}
\hline & At admission & $6 \mathrm{~h}$ after admission & $24 \mathrm{~h}$ after admission & $48 \mathrm{~h}$ after admission \\
\hline $\mathrm{pH}$ & 7.16 & 7.41 & 7.40 & 7.45 \\
\hline $\mathrm{PaO} 2$ (kPa) & 17.0 & 13.5 & 11.7 & 10.8 \\
\hline $\mathrm{PaCO} 2$ (kPa) & 2.5 & 3.4 & 4.2 & 5.0 \\
\hline Bicarbonate $(\mathrm{mmol} / \mathrm{l})$ & 9.2 & 18.3 & 20.4 & 26.5 \\
\hline Lactate $(\mathrm{mmol} / \mathrm{l})$ & 17.0 & 5.0 & 0.5 & 0.5 \\
\hline Sodium (mmol/) & 140 & & 138 & \\
\hline Potassium (mmol/l) & 3.9 & & 3.8 & \\
\hline Creatinine $(\mu \mathrm{mol} / \mathrm{l})$ & 65 & & 46 & 43 \\
\hline ALAT (IU/I) & 73 & 92 & 72 & 206 \\
\hline ASAT (IU/I) & 92 & 91 & 68 & 152 \\
\hline Lipase & & 61 & 584 & 126 \\
\hline $\begin{array}{l}\text { International Normalized } \\
\text { Ratio }\end{array}$ & 1.6 & 1.5 & 1.7 & 1.2 \\
\hline Fibrinogen $(\mathrm{g} / \mathrm{l})$ & & & 1.5 & 2.1 \\
\hline Factor $V$ activity & & & $26 \%$ & \\
\hline Leukocytes (g/l) & 18.1 & & 11.3 & 8.2 \\
\hline Haemoglobin $(\mathrm{g} / \mathrm{l})$ & 103 & & 86 & 91 \\
\hline Thrombocytes (G/l) & 392 & & 246 & 240 \\
\hline
\end{tabular}

Table 1: Evolution of blood tests.

Normal saline, bicarbonate, fresh frozen plasma, vitamin $\mathrm{K}$ and omeprazole were infused. Gastroscopy showed no active bleeding. A transthoracic echocardiogram showed normal cavities, good systolic function of both ventricles, and no valvulopathy. Urine screening for drugs was negative. Alcohol and metformin were undetectable in the blood.

The patient's haemodynamic instability did not recur, and confusion resolved. The lactic acidosis was corrected after $16 \mathrm{~h}$. Coagulation parameters normalized after $48 \mathrm{~h}$. Elevation of liver tests peaked 2 days after admission, as did pancreatic tests. Tests for viral or autoimmune hepatitis were negative, and ultrasound of the abdomen was normal.

When the patient was able to talk, she reported self-administration in increasing doses of nicotinamide (vitamin B3, Solgar) for the previous 10 days. For the last 4 days, she had been taking $4.4 \mathrm{~g}$ of nicotinamide daily. As an active member of the Association Suisse de l'Ataxie de Friedreich, she was informed of the results of the clinical trial previously cited ${ }^{[1]}$.

\section{DISCUSSION}

Administration of vitamin B3 in pharmacological doses is usually considered safe. Nicotinamide $\left(1.2 \mathrm{~g} / \mathrm{m}^{2}\right.$ up to a maximum of $\left.3 \mathrm{~g} / \mathrm{day}\right)$ has been administered to more than 250 patients for 5 years in a placebo-controlled randomized trial of diabetes prevention. Adverse events were comparable in the two arms, with no reported life-threatening events. Nicotinamide was well tolerated by the 10 patients included in the Friedreich's ataxia trial[1]. Only nausea and perturbation of liver function tests were reported.

However, severe adverse events have been reported following ingestion of high doses of nicotinamide or nicotinic acid. Some of the reported cases share similar clinical features. One patient had hypotension after ingestion of $11 \mathrm{~g}$ of nicotinic acid ${ }^{[2]}$. Mittal et al. described two cases of hepatotoxicity, metabolic acidosis and hypoglycaemia after ingestion of 5.5 and $2.5 \mathrm{~g}$ of nicotinic acid ${ }^{[3]}$. A 16-year-old boy developed severe hypoglycaemia, lactic acidosis, elevated liver tests and coagulopathy after taking $13 \mathrm{~g}$ of nicotinic acid ${ }^{[4]}$. We think that our patient experienced nicotinamide toxicity, because of the temporal association between the start of treatment and the appearance of symptoms, the strong similarity of the clinical and biological features with other reported cases, and the fact that symptoms resolved following withdrawal of the drug. Finally, no alternative explanation for the clinical picture was found despite extensive investigations. This case shows that severe adverse reactions are not restricted to the acidic form of vitamin B3, but can occur with the amide form as well.

Patients with orphan diseases often feel helpless because of the lack of medical knowledge and effective treatment for their condition. As a result of empowerment strategies, increasing use of the internet, and the development of patients' organisations, they are often well informed about their health condition and particularly involved in their own care and in research in the field ${ }^{[5]}$. Although desirable, these developments can lead to patients trying experimental drugs on their own initiative and exposing themselves to life-threatening events.

\section{CONCLUSIONS}

This case shows that severe adverse reactions are not restricted to the acidic form of vitamin B3, but can occur with the amide form as well. Unexpected severe adverse reactions not identified in preliminary clinical trials can occur when a new treatment is used in a less controlled setting. 


\section{REFERENCES}

1. Libri V, Yandim C, Athanasopoulos S, Loyse N, Natisvili T, Law PP, et al. Epigenetic and neurological effects and safety of high-dose nicotinamide in patients with Friedreich's ataxia: an exploratory, openlabel, dose-escalation study. Lancet 2014;384:504-513

Mularski RA, Grazer RE, Santoni L, Strother JS, Bizovi KE. Treatment advice on the internet leads to a life-threatening adverse reaction: hypotension associated with Niacin overdose. Clin Toxicol (Phila) 2006;44:81-84.

Mittal MK, Florin T, Perrone J, Delgado JH, Osterhoudt KC. Toxicity from the use of niacin to beat urine drug screening. Ann Emerg Med 2007;50:587-590.

4. Arcinegas-Rodriguez S, Gaspers MG, Lowe MC, Jr. Metabolic acidosis, hypoglycemia, and severe myalgias: an attempt to mask urine drug screen results. Pediatr Emerg Care 2011;27:315-317.

5. Ayme S, Kole A, Groft S. Empowerment of patients: lessons from the rare diseases community. Lancet 2008;371:2048-2051. 